\title{
Identifying, Categorizing and Setting Variables on Ergonomics Issues in Oil Palm Plantations
}

\author{
Normala S. Govindarajo ${ }^{1}$, Dileep Kumar M. ${ }^{1}$ \& Subrahmanium Sri Ramulu ${ }^{1}$ \\ ${ }^{1}$ Othman Yeop Abdullah Graduate School of Business (OYA-GSB), Universiti Utara Malaysia, Sintok, Malaysia \\ Correspondence: Normala S. Govindarajo, Othman Yeop Abdullah Graduate School of Business (OYA-GSB) \\ 123, Universiti Utara Malaysia, Sintok, Malaysia. E-mail: gnmala@uum.edu.my
}

Received: May 27, 2014 Accepted: June 21, 2014 Online Published: July 24, 2014

doi:10.5539/ass.v10n16p113 URL: http://dx.doi.org/10.5539/ass.v10n16p113

\begin{abstract}
It is an eye opening scenario that Malaysia turned to be one of the major producer and exporter of palm oil. Malaysia has witnessed a dazzling growth of $10.06 \%$ of its production recently from 4.05 million hectares in 2005 in an area of 54,000 hectares. Further, the production has enlarged from 94,000 tons in 1960 to 15 million tons in 2005, or by almost 160 times within 45 years-this represents a compound annual growth of $11.93 \%$ per year. The oil palm industry is labor intensive, since there is less adoption of mechanization in the field operations. Production of agriculture is usually associated with high incidence of ergonomic injuries, mainly during rigorous manual labor and throughout harvesting. Although scientific explanations are available, very less research was conducted to identify and fix variables that are closely related to ergonomics issues of workers in oil palm plantations related to workers absconding and disengagement from work. Field visits were conducted in the present study, to get an insight into the causal factors of ergonomics in relation to workers intention to abscond and disengagement in oil palm plantations was further congregated into. Thus an exploratory study was conducted in the oil palm plantations following qualitative research methods like direct interviews, focus group discussions and Delphi technique arrive at factors and categories related to the ergonomic issues of workers in oil palm plantations. The study provides better insight into the ergonomic issues of workers in oil palm plantations in the Sabah region of Malaysia.
\end{abstract}

Keywords: oil palm plantations, ergonomics, working condition, foreign workers

\section{Introduction}

In Malaysia, agriculture is being promoted as the third engine of growth and modernization for poverty reduction as stated in its latest ninth-5-year development plan (Ninth Malaysian Plan, 2006). However, Malaysia is facing issues of worker shortage in oil palm plantations and the country is extremely reliant on foreign workers coming from Indonesia and Philippines. Contextualizing the topic to the eastern part of Malaysia, the Sabah region of Malaysia, which is having $62.74 \%$ (268,992 people) foreign workers working in oil palm plantations, in comparison with the total Malaysia (450,396 people, in plantations). The question raised in this context is what is the reason behind these shortages of workers in oil palm plantations? It is pointed out in some of the literature that the issues are related to working and living conditions prevalent in the oil palm plantation in the country. While the others pointed out the reasons being ergonomic issues related to the agrarian work, in remote locations. This particular explorative study was focused more on the issues related to ergonomics in oil palm plantations which may lead many workers either to abscond, disengage or leave back to their country of origin due to physical working conditions. As we all know, farming and agriculture tasks are highly physical demanding, arduous and require extremely large of energy in performing their tasks. Hence, this poses farm workers at potential risk of health problems caused by physical hazards, chemical hazards, biological hazards, psychosocial hazards and ergonomic hazards. Ergonomic hazards pose a variety of musculoskeletal symptoms (MSS) encompasses the neck, low back pain, osteoarthritis of the hip and knee, upper limb complaints and hand-arm vibration syndrome (MTUC, 1989; Walker-bone et al., 2002). This study attempted to identify the ergonomic factors and its association with general working and living conditions of workers in oil palm plantations in Malaysia.

\section{Literature Review}

The oil palm industry encompasses 4 major activities, the upstream oil palm plantation, midstream processing, 
downstream application and research and development (R\&D). The upstream agricultural activities produce palm fruits that are rich sources of oil, while the midstream processing involves not only the extraction of crude and kernel oil but also biomass and animal feeds from the oil palm fruits and tree wastes. Thereafter, these intermediate products are then delivered to various industries for diversified downstream applications. In a special category by itself, $R \& D$, especially of biotechnology, has a major role to play in deriving various applications not only for downstream uses but also for the benefit of the upstream oil palm plantation benefits such as genetic manipulation of seeds, soil, fertilizers and plantation management, mechanization, etc. ( $\mathrm{Ng}$ et al., 2013).

\subsection{The Cycle of Oil Palm Plantation}

Usually, germination of oil palm seeds and management of seedlings a nursery is carried out prior to, or concurrently with the establishment of a plantation. After the land has been cleared off, soil work such as terracing, conditioning, irrigation, weeding and cultivation of cover crops are commenced. Once the land is prepared, the ready young palm seedlings are transplanted to the plantation. Subsequently, the plantation is managed for 3-4 years, during which weeding, pesticides and herbicides spraying, fertilizer application and pruning are carried out until the oil palm fruits, fresh fruit bunches are ready for harvesting. In a typical oil palm plantation, harvesting tasks are performed by a team of 2 workers, a fresh fruit bunch cutter and fresh fruit bunch collector, and as frequent as 3 cycles/visits per month are carried out for each tree. Harvested fruits are subsequently sent to an oil palm mill for oil extraction by truck, which is loaded separately by another category of workers known as loaders. Typically, an oil palm plantation has a lifespan of 25-30 years of production before fresh fruit bunch production finally declines to an unprofitable output level. Thereafter, the cycle of land clearing and preparation is repeated for replanting processes (Ng et al., 2013).

The findings in various studies (Rainbird \& O'Neill, 1995; Fathallah, 2010) have shown that labor-intensive agricultural practices have been associated with high prevalence of musculoskeletal disorder (MSD). In a review article, Kirkhorn, Earle-Richardson, and Banks (2010) highlighted the association of ergonomics risk factors and MSDs with the agricultural commodities. It can be observed that MSDs were prevalent among traditional manual harvesting practices.

\subsection{Ergonomics Issues}

As the oil palm trees grow, the height at which the FFBs are located increases correspondingly. At 6-7 years old, the fruits of the palm tree are approximately 3 meters above the ground. At this time, the fresh fruit bunches cutter uses either a chisel or sickle, switching among the two depending on whichever is more convenient for performing the job tasks. For trees beyond 7 years old, the fresh fruit bunches cutter will only use a sickle. At the height at this age, they naturally tilt their heads upward in order to locate ripe fruits (Ng et al., 2013).

\subsection{Ergonomic Problems during Harvesting: FFB Cutter}

It has been pointed out by Kotowski et al., (2003) that that oil palm harvesters are exposed to manifold ergonomics risk factors that leading to musculoskeletal disorders. This is factual in the case of fresh fruit bunch cutters stooping, that seems to be the most important posture at the initial phases of harvesting. Furthermore, for the period of cutting, the trunk and neck were also viewed to be somewhat rotated and being bent forward while the hand was vehemently pushing-pulling/swinging the chisel outside or across the body midline. The degree of the trunk flexion varies according to several factors, harvester's height; the height of the fresh fruit bunches on the palm trees and the work environment. In terms of work situation, the branches of fresh oil palm trees branch out in a canopy arrangement. This indirectly promotes further bending as harvesters avoid the pointy and sharp leaves of the palms which may cause cut-type injuries to the skin ( $\mathrm{Ng}$ et al., 2013). In the early stage of harvesting, the fresh fruit bunch cutter suffers especially from postural stress due to awkward postures and stooping in addition to forceful exertion and a rapid work pace. The body areas potentially affected during this harvesting stage is the lower back, upper back, hands and arms due to the nature of the job or task requirement, the worker harvests the oil palm fruit typically at knee level in the early stage ( $\mathrm{Ng}$ et al., 2013).

\subsection{Ergonomic Problems during Harvesting-FFB Collector}

The ergonomics issues are widely neglected by the plantations prior to the 20th century. It has been pointed out by Rainbird, et al., (2001) that musculoskeletal disorders and ergonomics in agricultural were an area deserted despite being the ones that warrant substantial attention. Further, Chapman L, \& Meyers J. (2001) report that the common view of health care providers was normally to emphasis on signs of pesticide exposure with the notion that musculoskeletal disorders occur in combination with agricultural manual work activities. Earlier reports have shown that harvesting tasks have been related to the risk of developing musculoskeletal disorders. These 
illnesses are typically the consequence of recurrent acquaintance to strain that develops slowly over time (Davis \& Kotowski, 2007). Mainly, pain in the hand, arms, shoulders, neck, back and waist are the most commonly reported symptoms in association with production agriculture (Kirkhorn et al., 2002; Sesto, 2012; Osborne et al., 2012). Several researchers have pointed out the risk factor associated with the oil palm work. Risk aspects such as rapid, repetitive motions, sustained static loading, awkward posture, externally applied compressive forces and vibration or any combination of them have also been reported to be stressful to one or more body regions (Kirkhorn et al., 2002; Sesto, 2012).

It is observed from the oil palm plantations that the plantation work is more labor intensive. It is reported that in the initial stages of harvests, a fresh fruit bunch cutter can weigh an average of about $5 \mathrm{~kg}$. Though, as the trees become older, the size and weights of fresh fruit bunches increase. This growth can be correlated with FFB of the oil palm tree at $>15$ years old weighing as much as $50 \mathrm{~kg}$. It has been pointed out by (Ng et al., 2013) in their study that during the initial stage of harvesting, the fresh fruit bunches cutter suffers particularly from postural strain due to awkward postures and stooping further to vigorous exertion and a high work pace. It is indicated that the body portion which would be drastically affected during this harvesting phase are the lower back, upper back, hands and arms due to the nature of the task or task requirement. Further referring to the injuries or disorders of the locomotive apparatus, the muscles, nerves, tendons, joints and cartilage, of the upper and lower limbs, neck and lower back, musculoskeletal disorders or work-related musculoskeletal disorders (Bernard et al., 2001) have commonly been associated with agricultural practices corresponding to rigorous labor-intensive work tasks in terms of a multitude of ergonomic risk factors (Fathallah et al., 2012).

Considering the related risk factors, the National Research Council and Institute of Medicine (2001) has proposed a conceptual model illustrating the complex interrelationship of workplace, organizational and social factors as well as individual factors that may contribute to the development of MSD. In addition, the harvesters may also concurrently be affected by different cultural, organizational, psychosocial and individual risk factors. Specifically, where foreign labor is involved, homesickness, health and socioeconomic well-being of the family as well as smoking habit and being overweight may increase the risk of developing an MSD. These risk factors have been shown in various studies to be significantly associated with MSD (Bernard et al., 1995; Sesto, 2012).

\section{Methodology}

\subsection{Interviews with the Workers}

\section{Worker 1}

I am Latif working in oil palm plantations almost 20 years. I came to Malaysia from Indonesia, when I come to know that I will, get good wages and benefits from plantation job. I have obtained this information about the job from my friend working in the same plantations during these days. I started working on harvesting and then with all kinds of activities in the plantations. As such the plantation job is very much taxing to my body and mind. Physical stress is very high. Since I am sending majority of the income to my family in Indonesia, I used to keep my health ignored. I am finding only one way to cope with this body pain is alcohol drinking habit. After having alcohol, I just sleep without realizing my body pain. Now I'm 38 my body can't handle as much target as last time when at the younger age. I am not at all engaged in harvesting job. Due to poor health condition I am allocated to pesticide spraying in plantations.

\section{Worker 2}

I have been working on the plantation job for the past 13 years. I am engaged in harvesting job. It's a tough job, as it needed healthy physique to bring down $20 \mathrm{kgs}$ of fruit from a tree, which very much taller than us. Due to our carelessness and some time because of poor equipment that we use in the harvesting activities we are exposed to several physical injuries. For the first week when I start holding the long cutter " tumbak" my hand was bleeding and skin torn off and in plantations the is little facilities to get the right aid in right time. Walking with the long "tumbak" and heavy tool we feel very much tired during the work. In order to reduce the high pacing, I have purchased a bicycle. But carrying heavy equipment and running the bicycle together is very much tedious task.

\section{Worker 3}

I'm Amnah 23, working as pesticide sprayer in the plantation for the past 5 years. The plantation manager grouped us into 25 to 30 people in a block with all the female workers. One "gendongan" tank that we carry as a bag pack of pesticide tank, which is having 15 litters and it takes around 30 to 45 minutes to complete the whole tank. It depends on the person's energy to complete the expected rounds of spraying. One person can maximize spray up to 10 rounds, which is equal to 150 liters $( \pm 150 \mathrm{~kg})$ per day. It gives me heavy pain in my lower back. 
Morning hours I used to find difficult to wake up due to heavy pain in the body. No option, I have to force myself to wake up or else I will lose my daily wage. It can't give enough rest over night to relief the pain. We do ask some "tukang urut" to massage with hot oil at least will give some relief to a good night's sleep. The plantation management never listens such stress and strain of employees.

\section{Worker 4}

I am Yati. I am also working here in the oil palm plantation as pesticide spraying worker. Every morning, we will gather at the plantation office. The Mandor assigns the location/block for pesticide spraying for each worker. The assembly time will start at $5 \mathrm{am}$ as everyone has to move to the assign block by $5.30 \mathrm{am}$. We will take a tractor to the block to undertake work in the assigned remote area. We will reach at the location later by $8 \mathrm{am}$. One female leader will be joining us to control over the pesticide and indirectly she will monitor us. Sometimes we might see snake "ular sawa" or wild pig. Attach from the wild life animals are quest common and we fear to engage work in interior locations. Water is limited for us to wash off the chemical stain at our body. We just have to be careful during our food. We don't have much choice. Due to our engagement with chemical substances, even when we clean our hands and body, there are higher chances to get our food contaminated. There is one time I had allergy problems on skin because of the chemical reaction. I went to the clinic nearby for treatment, only they have given some white cream. Many days I couldn't sleep very well due to itchiness and skin irritations.

\section{Worker 5}

I just started working as fertilizing "membajak" in oil palm plantation. I am trying to learn the job from my "makcik" aunty. I'm coming from Sulawesi my name is Idawati and just 17 years old. We are assigned in 10 people per group. In a block both male and females are mixed up to engage in plantation activities. We usually get 30 sacks of fertilizer and each sack has $50 \mathrm{~kg}$. We have to work as a team to complete the work. Everyone will be given pail that can contain $3 \mathrm{~kg}$ of fertilizer carry out the job. This activity involves high work pacing. Walking and carrying of the pail usually leads to pain at shoulders and hand area because of the movement of hand of throwing the fertilizer continuously. We have to wash our hands soon after the work, since the fertilizer act as the chemical, which is very strong can peel off our skin. I usually cause irritation in between the hand and leg fingers.

\section{Worker 6}

My name is Ali, 28 with 5 children and my wife working on daily bases with nursery at the plantation. I am working under the section on loading the palm oil fruit to the tractor or lorry. It has been 6 years in the plantation. Wage is quite good compared with other task in the plantation, except harvesting. Monthly I can earn up to RM1300. I am engaged in loading and unloading activities of fresh fruit bunches. It creates heavy neck, shoulder and body pain, since the tractor that is taller than me. One bunch of oil palm fruit is from $10 \mathrm{~kg}-20 \mathrm{~kg}$ it's so difficult to carry to the tractor. This is some time leading to conditions of breathlessness. Muscle crunch and Muscle pull are quest common.

\section{Worker 7}

I'm Hamza, 23 working on loading and unloading tasks in the plantation. I started working these plantations only about 3 months back. I don't have much experience in oil palm plantations work. I was a paddy farmer in my home country. What difference I felt from oil palm plantation work is the heavy physical labor which can be less replaced by machines and equipment. It needs to be run through human energy and teamwork. Sometimes I feel like to quit the job, and go back to my home country, due to heavy physical stress. But due to better wage, as compared to paddy field working in my home country, that prompts me to stay back here. During these few months I met with many injuries due to my lack of skill with the work assigned especially during loading and loading the fresh fruit bunch jobs and lead to a high infection. Sometimes the fruit fall on my foot, and caused injuries. It's really a tough job. My uncle told me to take "Jamu" (mix herbs by Indonesian) to regain the energy.

\section{Worker 8}

I'm a tractor driver at the plantation since 2011. I got the job because I know how to drive. It's quite fortunate for me to get a job, where I only need to drive the tractor to load and unload people, fertilizer and oil palm fruits. Although it sounds easy when people said it just driving. Lately I faced with many issues due to like, cold and fever, allergies and skin disorders, due to due to the dusty road. The plantation management never gives any safety helmet or equipment to protect the health. Due to dust infection, several times my eyes get infected, swollen become red. Compare to another task we are the first and the last person on the plantation to finish the job. Early morning I need to send the workers to respective block and in the late evening I have to them taken back them to their houses. In between time, I need to load fertilizer from store to plantation side. Body ache and 
back pain are quite common to us.

\section{Worker 9}

I'm Abbas Ali, 33 working in oil palm plantation almost 10 years. I have changed almost change 3 plantations. I'm working as a harvester for a contractor. I'm paid in "pajak"-piece rate as it depends on our hard work, and performance. I am putting my every effort to earn maximum from the plantation job, since I don't have any intention to stay back a few more years. I am separated from my family. I have to go back to my home country. I was very much healthy, when I came here. But due to heavy work and my interested to earn more made me to diminish my health condition. Since, due to heavy change in the climatic condition of in plantations like rainfall, humidity, and sunny days, and I used to face illness. Ignoring those illnesses I have to work, or else, mandor terminates my work.

\subsection{Research Questions}

The case analysis and the literature related to the ergonomic issues of the oil palm plantation s leading to several research questions or inquiries that need to be explored with proper research methods. In order to explore these concepts, the study posed three basic questions. They are:

1) How will you define ergonomics?

2) How will you define ergonomics issues?

3) Which are the factors related to ergonomics in oil palm plantations?

\section{Problem Formulation}

It is well pointed out various studies that the oil palm plantation work is highly labor intensive agricultural activities which not only leading to high physical disorders but also developing psychosomatic disorders. Many studies that incorporated the issues related to labor intensive practices leading Musculoskeletal (MSD). These disorders are prevalent among traditional harvesting process which is devoid of modern mechanization practices. Many human body postures during fresh fruit bunch (FFB) cutting leading to the trunk and neck disorders and cut type injuries to the skin. If you look into fresh fruit bunch collector issues due to awkward postures and stooping in addition to forceful exertion and a rapid work pace during the harvesting lead to many disorders like lower back pain, upper back pain, hands and arm injuries in the early stages. National Research Council and Institute of Medicine has indicated many factors causing the ergonomics issue leading to Musculoskeletal (MSD) in oil palm plantation workers like workplace factors, organizational factors, social factors as well as individual factors. Although those factors having identified by the past researchers many factors leading to ergonomics issues among workers in oil palm plantation is less research into. Moreover, the factors identified which are more related to body postures and activities ignoring issues related environmental factors, labor intensive-high task orientated physical labor and poor adoption mechanize tools and techniques. This indicates that there is still theoretical and methodological knowledge gap existing in studies related to ergonomics in oil palm plantation. Hence, contemporary a deep rooted study with the support of qualitative research is inevitable to identify the hidden factors related to ergonomics issues in oil palm plantations, leading to an extensive research incorporating the past variance and the hidden one which will be identified through this research.

\section{Problem Statement}

Hence, this particular study identifies its topic of research as identifying, categorizing and setting variables on ergonomics issues in oil palm plantations.

\section{4) Analysis and Result}

This particular study followed Delphi technique as it design of method to explore categories and factors related to ergonomics issues in oil palm plantation. As it is known, the Delphi technique is one of the method which started its usage in 1950's in order to get consensuses of opinion which is link to real world knowledge coming through experiences on the area related to research topics. It is pointed out by Dalkey (1972) that the consensus on decisions which is coming from heads is better than one, or... $n$ heads are better than one. This particular technique is as consider one of the effective communication process with the objective of making deep analysis base on deliberation on a specific problem in order to set the goal, under take a probe into the policy or to make effective prediction on the occurrence of future events. Basically Delphi technique is conducted in the form of semi structure interaction and interview. High concentration on the process is envisaged to ensure the rigorous. During mid of March to middle of November 2013 Delphi process organized among the resources people carefully selected based on the expertise knit with ergonomics and interviews where by. 20 experts from the Plantation Managers, Plantation Workers, Mandors of Plantations, Officers of Consulate Indonesia, Officers of 
Detention Centers, Officers of Immigration, Humana (NGO), Schools for Migrant Workers, Trade Union Leaders, Contractors of Housing, Faculty Members and Dean of Social Sciences Universiti Malaysia, Sabah (UMS), and Research Scholars were identified and approached by email or telephone and were invited to take part in the study. All the clarifications related to the objective of the study were made by the researcher. However, 30 respondents were being interacted and communicated, only 20 respondents shown their willingness to participate in the discussion. Finally, 20 participants were interviewed directly. The conversations taped recorded, and manually analyzed. The procedural steps in adopting the Delphi technique were as follows.

Expert panel identification: The group of professional was made from specialists having high knowledge and expertise in plantation related. They are closely associated with plantation, as consultants, government body, and Top level managers, NGO, Consulate, Professors, Researchers and Academicians. The specialized areas of these expert members include, 12 male members (60\%) and 8 female members (40\%). These dynamic groups of panel of experts are knowledgeable and familiar to give relevant opinions and an admissible understanding of the business incubation centers.

\subsection{Rounds}

\section{Round 1:}

In the first round, the Delphi process traditionally begins with an open-ended questionnaire. The open-ended questionnaire serves as the cornerstone of soliciting specific information about a content area from the Delphi subjects (Custer, Scarcella, \& Stewart, 1999).

\section{The questions:}

1) How will you define ergonomics?

2) How will you define ergonomics issues?

3) Which are the factors related to ergonomics in oil palm plantations?

\section{Round 2:}

The second round concentrate into categories and the items which are more closed to the concept ergonomics. Followed by the procedure the Delphi members where received the second questionnaire and accordingly they were required to rate or rank order the items in order to establish first level preferences among item incorporated into. In this stage, based on the decision and deliberation, agreement and disagreement on the items consider in relation to ergonomics were make. Care should be taken that, the number on Delphi iteration should be based on how far consensuses have been arrived at effectively on the concept ergonomics in the study. The process identifies 128 categories, which are having items with high and low proximity of ergonomics identified. Rating process further identified in the categories and items identified.

\section{Round 3:}

In the third round, each Delphi panelist receives a questionnaire that includes the categories and items ratings, summarized by the investigators in the previous round and are asked to revise his/her judgments or "to specify the reasons for remaining outside the consensus" (Pfeiffer, 1968). This round gives Delphi panelists an opportunity to make further clarifications of both the information and their judgments about the relative importance of the categories and items. Second level screening of the 128 categories which were having a high and low influence on ergonomics identified with corresponding items. The process further identified 64 categories, which are having high and low proximity of the ergonomics identified. Classification of the items in 64 categories of 2 factors was being made with appropriate loaded items. Thematic presentation and the categorization of the items were done.

\section{Round 4:}

This round is the last round in which the researchers tried to eliminate the minority opinion in order to capture the maximum level of consensus based on their rating on the categories and items which related to ergonomics. Cross checking of this categories and items were thoroughly make and the suitability clearly ascertained for fixing up the categories and items related the factor ergonomics. During fourth level, screening of the 30 categories which were having items with high and moderately high proximity of the ergonomics identified. Sought the expert opinion on the appropriateness of the core factors selected for the study 
Table 1. Ergonomic factor categories

\begin{tabular}{|c|c|c|c|c|c|}
\hline BIP S/N & Factors & Categories & No. Items & No of Experts $(\mathrm{N}=20)$ & \% of Experts \\
\hline \multirow{5}{*}{1} & \multirow{5}{*}{ Environment } & Frequent Climate variations & 2 & 17 & $85 \%$ \\
\hline & & High Humidity & 2 & 17 & $85 \%$ \\
\hline & & Heavy rain fall & 1 & 16 & $80 \%$ \\
\hline & & Dusty work atmosphere & 2 & 16 & $80 \%$ \\
\hline & & Danger from Wildlife & 1 & 15 & $75 \%$ \\
\hline \multirow{9}{*}{2} & \multirow{9}{*}{ Task } & Harvesting hazard & 1 & 18 & $90 \%$ \\
\hline & & Collecting heavy FFB & 2 & 18 & $90 \%$ \\
\hline & & Pruning related hazard & 3 & 18 & $90 \%$ \\
\hline & & Pesticide spraying & 2 & 18 & $90 \%$ \\
\hline & & Herbicides spraying & 3 & 18 & $90 \%$ \\
\hline & & Heavy use of fertilizing & 2 & 17 & $85 \%$ \\
\hline & & Planting work & 2 & 16 & $80 \%$ \\
\hline & & Too much walk-pacing & 2 & 18 & $90 \%$ \\
\hline & & Loading \& unloading heavy FBB & 2 & 18 & $90 \%$ \\
\hline \multirow{4}{*}{3} & \multirow{4}{*}{ Tools } & Poorly maintain equipment & 2 & 16 & $80 \%$ \\
\hline & & Heavy equipment & 3 & 18 & $90 \%$ \\
\hline & & Sharp equipment & 2 & 17 & $85 \%$ \\
\hline & & Use of Long equipment & 3 & 14 & $70 \%$ \\
\hline
\end{tabular}

The first factor considered for the study is the ergonomics problem in a plantation which divided into three factors environment, Task and tools used in the plantation. The experts acknowledged 6 items for the environment, 19 items in the task and 10 items for explaining the tools nature that's might affect the ergonomic of the workers. The major factor of environment consists of 5 categories. Frequent climate variations $(85 \%)$ and high humidity ( $85 \%)$ the two major categories in an environment under ergonomic, identified by the experts in the related to plantation setting. Second categories like dusty work atmosphere $(80 \%)$ and heavy rainfall $(80 \%)$. And the final categories in environment related factor is the danger from wildlife $(75 \%)$.

The second factor considered for the study is the task related directly to ergonomics. Within the second factor the experts identified 17 items that are closely related to Ergonomics. The major factor of task consists of 9 common categories. The table showed that harvesting hazard (90\%), collecting heavy FFB (90\%), pruning related hazards $(90 \%)$, pesticide spraying $(90 \%)$, herbicides spraying $(90 \%)$, loading and unloading heavy FFB $(90 \%)$ and too much walk's pacing $(90 \%)$ as the prominent factor which closely knit with ergonomics issue among workers. Further the study pointed out the categories like heavy use of fertilizing $(85 \%)$ and planting work $(80 \%)$ impact of ergonomic issues need to be highlighted. Besides that, tool use in the field indirectly imposed or contributed to ergonomics issues as identify by expert by 10 items and 4 categories which involved heavy equipment (90\%), sharp equipment $(85 \%)$, poorly maintain equipment $(80 \%)$, and use of long equipment $(70 \%)$.

The final factor considered for the study is the tools related directly to ergonomics. The experts have identified 10 items and 4 categories closely related to ergonomics. The major issues highlighted by experts is heavy equipment (90\%), sharp equipment (85\%), poorly maintain equipment $(80 \%)$ and use of long equipment $(70 \%)$.

\section{Discussion}

The objective of this particular research is to identify, categories and setting variables on ergonomics issues of workers in oil palm plantation. The study followed case analysis, interview, field observation and Delphi technique to extract factors related to ergonomics in oil palm plantation. The study highly follows Delphi Technique where the experts' opinion on causative factors and categories are relied upon. The experts identified three factors and 30 categories in relation to ergonomics issues. The factors identified include environmental factors, task related factors and tool related factors leading to ergonomics issues, worker disengagement and ultimately leading workers intention to leave. A detail discussion on these three factors incorporating 30 categories is pointed out as below.

The first factor identified by the experts included the environmental factor leading to worker ergonomics issues. The oil palm plantation is usually located in those are which are clear from forest location and such geographical 
location is vulnerable to heavy rainfall, frequent climate variation and high humidity. Due to interior remote location, and frequent climate variation the workers working in oil palm plantation are highly vulnerable to varied illness and health disorders. Fever, running nose, headache, diarrhea, skin disease etc. is quite common in among plantation workers. In addition to that, the workers are exposed to forest environment where they have to face challenges from wildlife animals like monkeys, snakes, scorpions, elephants etc. they have strength their body to protect themselves from various environmental issues during their working environment. Further, due to lack of sophisticated road and routes inside the plantation the workers are exposed to dusty work atmosphere leading to the respiratory issue, allergy and related physical disorders. Do the experts have identified the environmental factors as one of the major factors contributing to ergonomics.

The second major factor identified by the experts is related to the task in which plantations workers engage in. Major activities in which the workers are exposed in oil palm plantation involve upstream oil palm plantation work, midstream process and downstream application. The cycle of oil palm plantation starts with seeds and management of seedlings follow by that clearing of soil work activities such as terracing, conditioning, irrigation, winding and containers of cover crops follow by that pesticide and herbicides spraying, fertilizer application and pruning are carried out until the oil palm fruit ready for averting followed by these activities harvested fruits have to be sent to the oil palm mill by truck. All these activities are routine base and there is no change so far in relation to the nature of the job. The experts observed that all these activities involves high levels of body stretching, leaning, bending, flection of trunk, muscle pull, due to forceful action and rapid work best. The body areas potentially affected include lower back, upper back, hands and arms due to the nature of the job or task requirements. In addition to that, such task related activity is causing issue locomotors disorders of muscle, nerve tenderness, joints, and cartilage, or the upper and lower limps, neck and lower back, MSD or work related. MSD leads to high multitude of ergonomics risk factors. Especially the people engaged in loading and unloading activities are exposed to continue problem related to pain in the hands, arms, shoulders, neck, back, and waist leading to high ergonomics related issues. Thus, all the work activities in oil palm plantation are a susceptible ergonomic issue between workers in oil palm plantation.

The last factor identified by the experts includes the categories related to tools or equipment used by the plantation workers. It has been pointed out clearly by the experts that due to lack of mechanization and the usage of outdated or poorly maintain equipment used by the workers, this work force is continuously exposed to work related injuries and related ergonomics issues. Many activities like cutting, pruning, harvesting etc. required to appreciate the tools to handle the task associated with especially as the oil palm tree growing up, the height at which the fresh fruit bunches (FFB) are located also increases correspondingly at this time the FFB cutter uses a chisel, or sickles to do the task. Quite naturally they have tilted their heads in order to locate the right fruit $(\mathrm{Ng}$, Bahri, Syah, Mori, \& Hashim, 2013). Thus, the experts have identified clear variable related to tools and its implication on ergonomics issues.

These three factors like environmental factor, task related factor and tools related factor is leading to ergonomics issues in oil palm plantation that intern having a high effect on productivity and performance in oil palm plantation.

\section{Model Development}

The study has come out with a model which is having a direct relationship with the employee disengagement at work in oil palm plantations. It can be illustrated as.

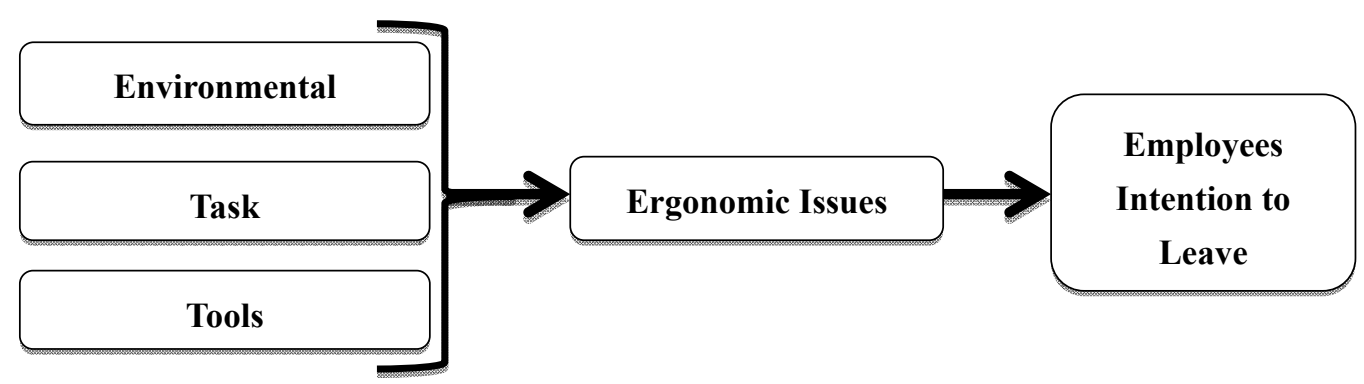

Figure 1. 


\section{Implications}

This particular study has far reaching implications for policy, managerial, methodological and theoretical level. Even though the effect of ergonomics issues like Musculoskeletal Disorders are well aware, the factors leading to such psychosomatic illnesses are less researched into. The literatures available from the plantations are no sufficient to arrive at appropriate inference about the issues related to ergonomics in oil palm plantations. Considering this factor, this particular research extent better theoretical framework to the existing literature through expert opinion regarding the issues related to ergonomics in oil palm plantation. Further the study pointed out important factors that can be considered by the plantation management to re-look into the work environment and technical support factor with which they can alleviate the somatic stress of employees working in the oil palm plantations. Accordingly, the study provides insight into the managerial implications of the outcomes. An adequate intervention to the said parameters may support employee attrition in oil palm plantations.

This particular study follows triangulation method to arrive at the result. The study followed case analysis, field observations, interviews and Delphi technique and integrated the result from all, the methodologies. All the result, with the application of varied methodologies in the qualitative research, is used and the results are correlated. The study could observe seldom any variation among the result. Hence the result provide better validity of the outcome and the plantation management can try for better intervention strategies that alleviate the somatic stress of employees working in the oil palm plantations.

Last but not least, the study further leading to the policy makers, especially the government to look into the results obtained from this research and force the plantation management to adopt mechanizations in oil plantation. Absence of proper mechanization and the use of outdated equipment are the major reason related to employee absconding or their intention to leave from the plantation jobs. The study also envisages appropriate steps from the government side to ensure proper monitoring in plantation sector that even attract the local employees to join in the work in the oil palm plantations.

\section{Conclusion}

This particular research was conducted to identify and fix variables related to ergonomics issues in oil palm plantations. The study has observed major three factors that contributing to ergonomic issues in oil palm plantations. In order to arrive these factors the researchers followed the Delphi technique, short case analysis through interviews and field observation. The study identified 18 categories under 3 factors related to the theme, ergonomic issues. The study thus gives an insight into the antecedents of ergonomic issues of workers in oil palm plantations. These ergonomic issues are creating challenges to the workers to stay back in the organization or it leads to employee's intention leave plantation jobs and take up alternative employment opportunities in small holding oil palm plantations. The issues are not much different in large scale plantations. The triangulation method's applicant in the research provides better validity to the construct. It is envisaged here in this context that wider research with the support of quantitative research to be conducted with the identified factors, categories and the items to ensure more reliability to the outcomes.

\section{References}

Bernard, B. P., Putz-Anderson, V., \& Burt, S. E. (1997). A critical review of epidemiologic evidence for work-related musculoskeletal disorders of the neck, upper extremity, and low back. Cincinnati (OH): Centers for Disease Control and Prevention National Institute for Occupational Safety and Health Publication. pp. 97-141.

Chapman, L., \& Meyers, J. (2001). Ergonomics and musculoskeletal injuries in agriculture: Recognizing and preventing the industry's most widespread health and safety problem. Agricultural Safety and Health Conference Proceedings. March 2-3, Baltimore (MD).

Custer, R. L., Scarcella, J. A., \& Stewart, B. R. (1999). The modified Delphi technique: A rotational modification. Journal of Vocational and Technical Education, 15(2), 1-10.

Davis, K. G., \& Kotowski, S. E. (2007). Understanding the ergonomic risk for musculoskeletal disorders in the United States agricultural sector. American Journal of Indigenous Medicine, 50, 501-511. http://dx.doi.org /10.1002/ajim.20479

Fathallah, F. A. (2010). Musculoskeletal disorders in labor-intensive agriculture. Applied Ergonomics, 41, 738-743. http://dx.doi.org/10.1016/j.apergo.2010.03.003

General Association of Engineers in Romania, (AGIR). (2012). Musculoskeletal Disorders in Agriculture. 
Retrieved October 15, 2012, from http://www.agir.ro/buletine/1276.pdf

Kirkhorn, S. R., Earle-Richardson, G., \& Banks, R. J. (2010). Ergonomic risks and musculoskeletal disorders in production agriculture: Recommendations for effective research to practice. Journal of Agro medicine, 15, 281-299. http://dx.doi.org/10.1080/1059924X.2010.488618

Kumar, D. M. (2013). Ways and Means of Research Method. Research India Publication. New Delhi, India.

Malaysian Trade Union Congress (MTUC) and International Federation of Free Trade Union (ICFTU). (1989). Laporan Kajian Occupational Health and Safety Issues in Malaysia.

Meyers et al. (2002). Priority risk factors for back injury in agricultural field work: Vineyard ergonomics. Journal of Agro medicine, 8, 39-54. http://dx.doi.org/10.1300/J096v08n01_05

National Research Council. (2001). The Institute of Medicine. Musculoskeletal disorders and the workplace: Low back and upper extremities. Washington, DC: National Academy Press.

Ng, Y. G., Bahri, M. T. S., Syah, M. Y. I., Mori, I., \& Hashim, Z. (2013). Ergonomics Observation: Harvesting Tasks at Oil Palm Plantation. Journal of Occupational Health, 55, 405-414. http://dx.doi.org/10.1539 /joh.13-0017-FS

Osborne et al. (2012). Prevalence of musculoskeletal disorders among farmers: A systematic review. American Journal of Indigenous Medicine, 55, 143-158. http://dx.doi.org/10.1002/ajim.21033

Pfeiffer, J. (1968). New look at education. Poughkeepsie, NY: Odyssey Press.

Rainbird, G., \& O'Neill, D. (1995). Occupational disorders affecting agricultural workers in tropical developing countries: Results of a literature review. Applied Ergonomics, 26, 187-193. http://dx.doi.org/10.1016/00036870(95)00016-6

Sesto, M. (2000). Chronic Musculoskeletal Disorders in Agriculture for Partners in Agricultural Health. University of Wisconsin-Madison. Retrieved October 15, 2012, from http://www.worh.org/files/AgHealth/ musc.pdf

Solecki, L. (2001). Current state of ergonomics in agriculture--future needs. VIII International Symposium on Ergonomics, Work Safety and Occupational Hygiene. 22-24 October 2001, Lublin. Annual Agricultural and Environmental Medicine, 8, 297.

Walker-bone, K., \& Palmer, K. T. (2002). Musculoskeletal disorders in farmers and farm workers. Journal of Occupational Medicine, 52(8), 441-450. http://dx.doi.org/10.1093/occmed/52.8.441

\section{Copyrights}

Copyright for this article is retained by the author(s), with first publication rights granted to the journal.

This is an open-access article distributed under the terms and conditions of the Creative Commons Attribution license (http://creativecommons.org/licenses/by/3.0/). 